\title{
The Effect of Individual Factors on the Medication Error
}

\author{
Amr H. Zyoud ${ }^{1}$ \& Nor Azimah Chew Abdullah ${ }^{1}$ \\ ${ }^{1}$ School of Business Management, Universiti Utara Malaysia (UUM), Kedah, Malaysia \\ Correspondence: Amr H. Zyoud, Nor Azimah Chew Abdullah, School of Business Management, Universiti \\ Utara Malaysia, Sintok, 06010, Kedah, Malaysia. Tel: 60-013-464-0928. E-mail: amr.zyoud@gmail.com; \\ norazimah@uum.edu.my
}

\author{
Received: February 27, 2016 Accepted: March 20, 2016 Online Published: April 29, 2016 \\ doi:10.5539/gjhs.v8n12p197 URL: http://dx.doi.org/10.5539/gjhs.v8n12p197
}

\begin{abstract}
Medication error is a major issue in healthcare industry and significant efforts have been taken in recent years to comprehend factors that influence errors in medication. Therefore, the present study aims to examine individual factors that contribute to medication errors as perceived by nurses. 255 registered nurses working in different Jordanian public hospitals have been chosen as samples to collect the study data from. They were asked to complete a questionnaire to assess the perceived individual factors, specifically, on nursing mathematical calculation skills and training as well as knowledge on medication treatment as factors contributing to medication errors. The current study found that the nurses' mathematical calculation skills, training and their knowledge on medication treatment have significant relationship with medication error. This was proven as the study framework is able to explain $45.6 \%$ of the total variance. Consequently, it is recommended that healthcare authorities and hospitals in Jordan should focus on nursing knowledge in medication treatment and the nurses' ability to perform drug calculation in order to improve the medication system in Jordan.
\end{abstract}

Keywords: medication errors, knowledge, mathematical ability, Jordanian nurses

\section{Introduction}

Medication treatment is a fundamental element in the treatment of illnesses (Kelly, 2004). It is a multi-disciplined practice which requires synchronized efforts and participation of healthcare professionals to carefully distribute medicine to patients without causing any injury (Manojlovich \& DeCicco, 2007). Nurses are responsible for a major part of this process of administering medication to patients (Brady et al., 2009). Studies have reported that medication treatment is encompasses $40 \%$ of nurse's daily duties (Armitage \& Knapman, 2003). According to Scott (2002), medication error rate has increased significantly over the preceding decade by $500 \%$. A study by Taxis and Barber (2003) outlined that the frequency of medication error is yet further prevalence with $50 \%$ of medication treatment involving error.

Previous reports in America stated that fatal injures caused by medical error has exceeded 44,000 patients each year leading to expenditure exceeds 17 billion US dollar (Kohn, Corrigan, \& Donaldson, 2000). This has made medication error considered as the most common form of medical errors (Hayajneh, AbuAlRub, \& Almakhzoomy, 2010; Kaushal et al., 2001).

Gurwitz et al. (2000) reported that 350,000 medication errors in the US occurred at the community base health facilities alone and $50 \%$ of those medication errors were preventable errors. Likewise, another study reported that about 1.9 million medical errors take place in the US every year (Gurwitz et al., 2005). Moreover, a review of European studies stated that $19-28 \%$ of patients are suffering from medication errors at one point of their hospitalization period (Johnstone \& Kanitsaki, 2006).

Jordanian hospitals are also not sparred from this pattern. A study conducted in Jordanian hospitals which assessed medication errors from nursing point view estimated that each nurse experienced about 2.2 medication errors during their career (Mrayyan, Shishani, \& Al-Faouri, 2007). Another study in 2008 also found that nurses experience more than 6 errors throughout their professional career (Mrayyan, Shishani, Faouri, \& Ammouri, 2008). Other studies in Jordan reported that nearly $28 \%$ of patients admitted to Jordanian hospitals suffered from medical error. The study also suggested that $58 \%$ of those medical errors were medication errors which make them the most prevalence medical errors in Jordan (Hayajneh et al., 2010).

Even though there are many cases reported on medication error, many literature showed that the area of 
medication error is relatively vague and there are very limited studies regarding the causal factors for medication error (Flynn, Liang, Dickson, Xie, \& Suh, 2012; Mrayyan et al., 2007). Indeed, it is a very complex process to identify the factors that cause medication error as pointed out by Armitage and Knapman (2003), but in order to successfully address the issue, a lot more studies should be done and focused on understanding the reason behind the occurrence of medication errors.

Nurses usually are 'the last connection in the drug treatment chain' before medication errors can occur to patient. Therefore nurses usually have been held responsible for errors (Keers, Williams, Cooke, \& Ashcroft, 2013).

Medication error contributing factors could be classified into three categories: individual, contextual and knowledge-based (Hand \& Barber, 2000). However, individual attributes have been mainly looked at as being responsible for medication error, since nurses have a primary role in the medication process (Wakefield, Uden-Holman, \& Wakefield, 2005).

These factors include: demographic characteristics, education level, experience and the psychological conditions of nurses (Mrayyan et al., 2007). Nevertheless, most of these individual attributes have been found to be not significantly related to error in the medication treatment process. In addition, the association which link nurses' individual factors and medication error was weak (Mayo \& Duncan, 2004).

Moreover, a lot of studies also highlighted other individual factors contribute to medication errors such as medication calculations ability, the level of knowledge and proficiency in medication treatment process, the neglect of medication protocol of their institution as a result of heavy workload, insufficient work experience and unsuitable work environment (Alsulami, Conroy, \& Choonara, 2013).

Individual factors can play a substantial role in nurses' decision making process and influence their professional judgment, leading to medication error (Armitage \& Knapman, 2003). Hence, individual factors are an essential aspect of human judgment from the perspective of the medication process (Veazie, 2006)

Generally, medication errors can occur in any stage of the medication treatment process, although a significant number of errors occur at medication administration stage (Al-Shara, 2011). Furthermore, studies on empirical findings suggest that insufficient knowledge in pharmacology and medication preparation are the most common obstacles that nurses encountered during the medication administration stage (Cowley, Williams, \& Cousins, 2001; Lan et al., 2014)

Nurses' knowledge on medication and their ability to perform precise drug calculation is one of the most important factors to ensure their competence in performing medication treatment to patient in correct and safe manner (Ehsani et al., 2013)

According to Alsulami et al. (2013), a systematic review of 12 different studies that investigate factors which contribute to medication errors has reported that the most common contributing factors of medication errors were poor knowledge in medication, medication preparation, medication calculation and medication administration.

Other studies also have highlighted that nurses' knowledge on the medication process as well as correct dosages and administration method are the most significant factors affecting medication errors (Armitage \& Knapman, 2003; Ehsani et al., 2013; Lan et al., 2014; Tang, Sheu, Yu, Wei, \& Chen, 2007; Wakefield et al., 2005; Webster \& Anderson, 2002).

As pointed by Armitage and Knapman (2003), Capriotti (2004), Mrayyan et al. (2007), O'Shea (1999), and Wright (2010), the ability of nurses in calculating drug dosages and training is vital in the medication administration process. Nurses with poor mathematical skills will likely increase the risk of error in calculating dosages due to the complexity of drug calculation and the need to stick with precise medication dosage. Many studies have outlined that incorrect dosage as one of the most common medication error (Cowley et al., 2001; Lan et al., 2014).

Nurse's knowledge in medication administration process can improve knowledge-based and skill-based levels in problem solving ability during the medication administration process (O'Shea, 1999; Reason, 1990). Additionally, nurses with better knowledge in medication will help them to deal with problems at higher level which eventually will lead to lower chance of error occurrence (Armitage \& Knapman, 2003; Brady et al., 2009; Hoffman \& Proulx, 2003; O’Shea, 1999).

Nurses are required to possess adequate knowledge of drugs action mechanism, side effects and correct method of administration due to the fact that they are accountable for most of the administration process. Nevertheless with the increasing number of available medication and different administration methods in hospitals, nurses have the responsibility to update their knowledge regarding any new information concerning medication 
treatment process (Alsulami et al., 2013; Lan et al., 2014; O'Shea, 1999). Keeping that in mind, this study investigates the influence of nurses' mathematical calculation skills and training and their knowledge on medication treatment in causing medication error.

\section{Methodology}

\subsection{Sample, Setting, and Design}

The present study uses a cross-sectional descriptive correlational design and received ethical permission from the Ministry of Health in Jordan for data gathering. The data gathering procedure began in March 2015 and completed by July 2015. A total of 495 questionnaires were distributed, yet only 255 valid questionnaires were collected or $56.3 \%$ of respondent rate.

The study took a sample of nurses who work in three public hospitals in Jordan whom were selected through cluster random sampling technique. The study's sample criteria were registered nurses who had worked in hospital setting for a minimum period of six months and who are involved in direct patient care. These two criteria were set to guarantee the necessary level of competence and experience in the medication process and to ensure that nurses had sufficient experience to be competent in medication treatment process.

\subsection{Research Instrument}

The present study used a correlational survey. The questionnaire includes 25 items that reflects the study's three key constructs, which are medication error as the dependant variable and two independent variables. While the individual conditions constructed of nursing calculation skills and training and knowledge of medication administration process. The questionnaire was consisted of 4 parts:

\subsubsection{Medication Error}

According to Beyea, Hicks, and Becker (2003), this term was defined as a mistake in any stage of the medication process: ordering, transcription, dispensing, and administration, and discharge summaries, which included incorrect as well as missing procedures. Medication error was assessed using the modified Gladstone's scale (Mrayyan et al., 2007) which used 10 items that evaluate nurses' self-reported perceptions of medication errors, using Likert-type scale with response ranging from "7=strongly agree" to " $1=$ strongly disagree".

\subsubsection{Nursing Calculation Skills and Training}

This term was defined as nurse's perception of the level of mathematical ability and training that is required in the process of medication administration (Mayo \& Duncan, 2004). The 10 items adopted from Mayo and Duncan (2004), the instrument using seven points Likert-type scale ranging from "7=strongly agree" to " 1 =strongly disagree".

\subsubsection{Knowledge of Medication Administration Process}

This knowledge was defined as nurses' perception on the level knowledge required to ensure correct completion of drug administration process (Minick et al., 2000; as cited in Chang, 2007). This factor was assessed with five items using seven points Likert-type scale ranging from " $7=$ strongly agree" to " $1=$ strongly disagree".

\subsubsection{The Demographic Characteristics}

The demographic characteristics in this study consist of gender, age, years as registered nurse (RN), education qualification of the respondent, years of employment, the area of work, and work hours per week.

After confirming the content-face validity, a pilot study was done to assess the appropriateness of tool to the study settings to establish the reliability and validity of the instrument. Cronbach's alpha was used to evaluate the reliability of the present study scales and the score were 0.78 and higher for the entire study instrument variables.

\subsection{Data Analysis}

Descriptive data (including study respondents' characteristics and study constructs) were obtained using SPSS software (SPSS version 20). The current study used Partial Least Squares-Structural Equation Modeling (PLS-SEM version 2.0) to evaluate the measurement model and structural model of the present study.

\section{Results}

The findings show that more than half of the respondents (144 registered nurses) were female nurses or $56 \%$. The majority of the study sample fits in to the age category of 30-39 years old, and about $30 \%$ of the respondents have worked as RN for 3-5 years. Majority of the respondents ( $80 \%$ ) had bachelor's degree and a total of $29 \%$ of them have working experience of 1-3 years. For the hospital work area, about $57 \%$ of respondents are working in 
the medical, surgical, maternity and pediatric units while the majority of nurses $(89 \%)$ work for more than 40 hours per week. Table 1 illustrates the demographic characteristics of the participants.

Table 1. Demographic characteristics of the participants

\begin{tabular}{|c|c|c|}
\hline & Number & Percentage \\
\hline \multicolumn{3}{|l|}{ Gender } \\
\hline Male & 111 & 44 \\
\hline Female & 144 & 56 \\
\hline \multicolumn{3}{|l|}{ Age } \\
\hline Under 30 years old & 111 & 43 \\
\hline 30-39 years old & 114 & 45 \\
\hline 40-49 years old & 22 & 9 \\
\hline 50 and above years old & 8 & 3 \\
\hline \multicolumn{3}{|l|}{ RN Licenses } \\
\hline Less than 1 year & 17 & 7 \\
\hline $1-3$ years & 59 & 23 \\
\hline $3-5$ years & 77 & 30 \\
\hline $5-10$ years & 59 & 23 \\
\hline $10-20$ years & 34 & 13 \\
\hline More than 20 years & 9 & 4 \\
\hline \multicolumn{3}{|l|}{ Degree } \\
\hline Bachelor's in Nursing & 204 & 80 \\
\hline Master's in Nursing & 45 & 18 \\
\hline Doctorate in Nursing & 6 & 2 \\
\hline \multicolumn{3}{|l|}{ Employment } \\
\hline$<1$ year & 27 & 11 \\
\hline $1-3$ years & 75 & 29 \\
\hline $3-5$ years & 33 & 13 \\
\hline $5-10$ years & 62 & 24 \\
\hline $10-20$ years & 51 & 20 \\
\hline$>20$ years & 7 & 3 \\
\hline \multicolumn{3}{|l|}{ Area } \\
\hline Medical/Surgical & 84 & 33 \\
\hline Intensive Care (ICU) & 73 & 29 \\
\hline Maternal/Women's & 32 & 13 \\
\hline Pediatrics & 18 & 7 \\
\hline Emergency & 25 & 10 \\
\hline Operation Room & 10 & 4 \\
\hline Others & 13 & 5 \\
\hline \multicolumn{3}{|l|}{ Hour per week } \\
\hline 24 to 30 hours/week & 2 & 1 \\
\hline 31 to 40 hours/week & 25 & 10 \\
\hline Over 40 hours/week & 228 & 89 \\
\hline
\end{tabular}

Table 2 represents the analysis of 255 valid cases of the study. Specifically, medication error mean and standard deviation were 4.19 and 1.32 respectively which suggest that the respondents experience a moderate level of medication error in their units. Also, the outcome indicates a moderate level for nurses' mathematical calculations skills at a mean of 4.47 and a standard deviation of 1.31. The result for nurses' knowledge indicates 
a moderate level with mean of 4.34 , and standard deviation of 1.40 .

Table 2. Descriptive statistics of the study variables

\begin{tabular}{lll}
\hline Latent Variables & Mean & Std. Deviation \\
\hline Medication Error & 4.19 & 1.32 \\
Nurses knowledge & 4.34 & 1.40 \\
Nursing mathematical skills & 4.47 & 1.31 \\
\hline
\end{tabular}

The present study had adopted two steps of PLS path process. The first step is the assessment of a measurement model, and the second step is the assessment of a structural model (Hair, Ringle, \& Sarstedt, 2011; Hair, Hult, Ringle, \& Sarstedt, 2014). Moreover, the present study completed the evaluation of the measurement model and established its validity and reliability (as shown in Figure 1).

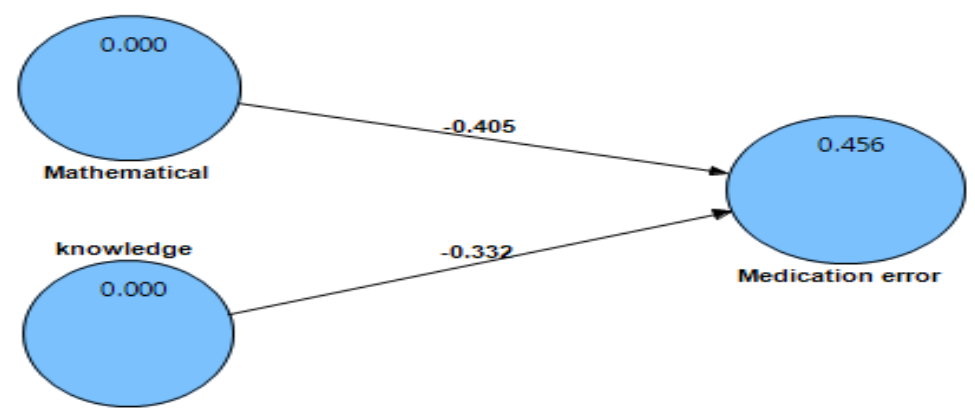

Figure 1. Measurement Model

Further, the present study assessed the significance of the path coefficients by applying bootstrapping method with 5000 bootstraps (Hair et al., 2014; Hair et al., 2011; Henseler, Ringle, \& Sinkovics, 2009), (Figure 2 and Table 3 report the full estimation of the study's structural model).

Nurses' mathematical calculation skills and nursing knowledge of medication are both significantly associated with medication error. Specifically, the findings as shown in (Table 3 and Figure 2) revealed a significantly negative association between the nurses' mathematical calculations skills and training in medication administration process and medication error $(\beta=-0.405, \mathrm{t}=5.991, \mathrm{p}<0.001)$. Furthermore, the current study findings (Table 3, Figure 2) demonstrated a significantly negative relationship between nurses' knowledge in the medication administration process and medication error $(\beta=-0.332, \mathrm{t}=4.941, \mathrm{p}<0.001)$.

Table 3. Structural model assessment with moderator (full model)

\begin{tabular}{llllll}
\hline Hypotheses & Relation & Beta & SE & t-value & p-value \\
\hline H1 & ME->Nurses mathematical skills & -0.405 & 0.068 & 5.991 & $0.000^{* * *}$ \\
H2 & ME->Nurses knowledge & -0.332 & 0.068 & 4.941 & $0.000^{* * *}$ \\
\hline
\end{tabular}

Note. ${ }^{* * *}$ Significant at 0.01 (1-tailed), ${ }^{* *}$ significant at 0.05 (1-tailed), *significant at 0.10 (1-tailed)

Based on the findings, The current study's model, which constructed of nurses mathematical skills and nurses knowledge, is statistically significant and has explained about $46 \%$ (R-squared value) of the total variance in the dependent variable (medication error) (see Figure 1). Consequently, the endogenous latent variable reports a moderate level R-squared value which is considered an acceptable level following Chin (1998) criteria. The highest negative contribution in predicting medication error was done by Nurses mathematical skills ability and training $(\beta=-0.405, \mathrm{p}<0.001)$; while knowledge in the medication administration process $(\beta=-0.332, \mathrm{p}<0.001)$. 


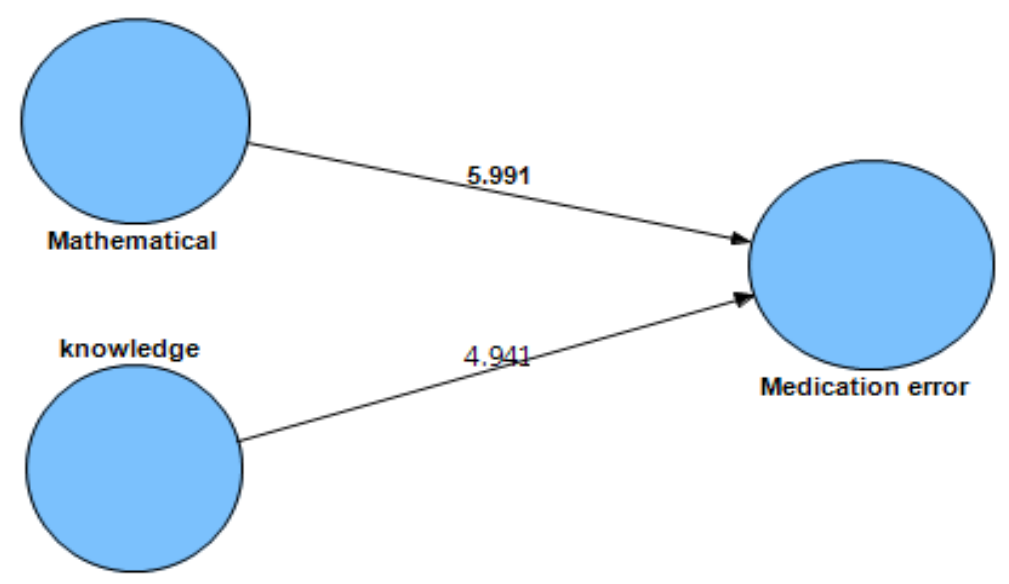

Figure 2. Structural Mode

\section{Discussion}

The present study aims to shed light on individual conditions that can produce medication error in the context of the nurses' workplace. And it is more particular on the influence of mathematical calculation ability and training as well as nursing knowledge in medication administration process on medication error. It is therefore clear that the nurses' mathematical calculation skills are vital in the process of medication treatment due to the complexity of drug dosage calculation and the need to adhere to a precise drug regimen (Alsulami et al., 2013).

Hence, lower calculation skills can increase the risk of medication error (Cowley et al., 2001; Lan et al., 2014). This result seems to be consistent with previous studies that reported a negative association between medication error and mathematical calculation skills of nurses (Armitage \& Knapman, 2003; Capriotti, 2004; Mrayyan et al., 2007; O'Shea, 1999; Wright, 2010). Moreover, the calculation ability in nursing practice nurses working with high alert drugs where there is a necessity for weight-based drug dosing and multiple calculations, dilution of drug with solutions is extremely important (Cowley et al., 2001; Tang et al., 2007).

Secondly, the present study finds that nurses' knowledge in medication is significantly correlated in a negative manner with medication error which is consistent with the findings of previous studies by Armitage and Knapman (2003), Brady et al. (2009), Hoffman and Proulx (2003), Lan et al. (2014), and O'Shea (1999). Furthermore, prior studies have reported that knowledge in medication treatment can develop the individual level of cognitive judgment (Reason, 1990). Definitely, nurses with advanced knowledge in medication treatment process would develop knowledge-based practices and improve their nursing skills which can lead to better problem solving ability, and eventually decreasing the chances of committing medication error (O'Shea, 1999; Reason, 1995).

In addition, advanced knowledge will improve their ability to deal with problems at a higher theoretical level in the medication treatment process, hence reducing the possibility of medication error (Chang \& Mark, 2009; O'Shea, 1999). This is beneficial when dealing with pediatric patients. Due to their immature and distinctive condition of physiological development, they require drug preparation and administration that different from adult patients (Lan et al., 2014). Therefore nurses need to have sufficient knowledge regarding pediatric medication treatment to safely perform medication administration process.

The study's framework is able to explain only $45.6 \%$ of the total variance, which indicates that other conditions exist, that contribute to medication error which are not considered in this study. More specifically any systematic conditions that go beyond the individual aspect which can influence medication error through the system's operational process that need to look into (Reason, 2000; Vincent, Taylor-Adams, \& Stanhope, 1998). Future studies should also consider other possible conditions that could influence nurses to cause medication error, and therefore be viewed as having behaved unprofessionally.

The present study has a number of methodological limitations, those which should be considered when attempting to generalize the findings made. This includes the low response rate (only 56\%) and the small sample size (255). Moreover, the respondents are primarily from public hospitals in the Jordanian health sector. Future studies should consider expanding the sample to include private and teaching hospitals. Lastly, this study adopts a cross-sectional method in data collection which future studies should apply a longitudinal design to assess 
these factors at various points in time.

\section{Conclusion}

This study examines the relationship between nurses' individual conditions and medication error in Jordan. The findings lend support to the nursing profession in general, and specifically, to policymakers, to understand factors contributing to medication error. Furthermore, this study discussed that mathematical proficiency of nurses and their knowledge of the medication treatment process have a significant correlation with medication error. Therefore, healthcare organizations and educational centers in Jordan should give attention to these factors to establish he nurses' professionalism in the medication administration process and to decrease the rate of medication error.

The present study's model also showed only $46 \%$ of variance therefore, future studies should expand the theoretical framework to comprehend other contributing factors to explain the remaining $54 \%$ of the variance in medication error by incorporating a border scope that goes beyond the individual perspective to a more holistic perspective that incorporates the entire medical system. It is also suggested that future studies can simulate this study by using a larger population and more diverse scope in the healthcare field.

\section{Competing Interests Statement}

The authors declare that there is no conflict of interests regarding the publication of this paper.

\section{References}

Al-Shara, M. (2011). Factors contributing to medication errors in Jordan: A nursing perspective. Iranian Journal of Nursing and Midwifery Research, 16(2), 158-161.

Alsulami, Z., Conroy, S., \& Choonara, I. (2013). Medication errors in the Middle East countries: A systematic review of the literature. European Journal of Clinical Pharmacology, 69(4), 995-1008. http://dx.doi.org/ 10.1007/s00228-012-1435-y

Armitage, G., \& Knapman, H. (2003). Adverse events in drug administration: A literature review. Journal of Nursing Management, 11(2), 130-140. http://dx.doi.org/10.1046/j.1365-2834.2003.00359.x

Beyea, S. C., Hicks, R. W., \& Becker, S. C. (2003). Medication errors in the OR-a secondary analysis of Medmarx. AORN Journal, 77(1), 122-134. http://dx.doi.org/10.1016/S0001-2092(06)61382-3

Brady, A.-M., Redmond, R., Curtis, E., Fleming, S., Keenan, P., Malone, A.-M., \& Sheerin, F. (2009). Adverse events in health care: A literature review. Journal of Nursing Management, 17(2), 155-164. http://dx.doi.org/10.1111/j. 1365-2834.2008.00887.x

Capriotti, T. (2004). Basic concepts to prevent medication calculation errors. Dermatology Nursing/Dermatology Nurses' Association, 16(3), 245-248.

Chang, Y. (2007). Testing a Theoretical Model for Severe Medication Errors. (Doctoral dissertation).

Chang, Y., \& Mark, B. (2009). Antecedents of severe and nonsevere medication errors. Journal of Nursing Scholarship, 41(1), 70-78. http://dx.doi.org/10.1111/j.1547-5069.2009.01253.x

Chin, W. W. (1998). The partial least squares approach to structural equation modeling. In G. A. Marcoulides (Ed.), Modern methods for business research (pp. 295-336). Mahwah, NJ: Lawrence Erlbaum Associates.

Cowley, E., Williams, R., \& Cousins, D. (2001). Medication errors in children: A descriptive summary of medication error reports submitted to the United States Pharmacopeia. Current Therapeutic Research, 62(9), 627-640. http://dx.doi.org/10.1016/S0011-393X(01)80069-2

Ehsani, S. R., Cheraghi, M. A., Nejati, A., Salari, A., Esmaeilpoor, A. H., \& Nejad, E. M. (2013). Medication errors of nurses in the emergency department. J Med Ethics Hist Med, 24(6), 11.

Flynn, L., Liang, Y., Dickson, G. L., Xie, M., \& Suh, D. C. (2012). Nurses' practice environments, error interception practices, and inpatient medication errors. Journal of Nursing Scholarship, 44(2), 180-186. http://dx.doi.org/10.1111/j.1547-5069.2012.01443.x

Fry, M. M., \& Dacey, C. (2007). Factors contributing to incidents in medicine administration. British Journal of Nursing, 16(9), 556-559. http://dx.doi.org/10.12968/bjon.2007.16.9.23435

Gurwitz, J. H., Field, T. S., Avorn, J., McCormick, D., Jain, S., Eckler, M., ... Bates, D. W. (2000). Incidence and preventability of adverse drug events in nursing homes. The American Journal of Medicine, 109(2), 87-94. http://dx.doi.org/10.1016/S0002-9343(00)00451-4 
Gurwitz, J. H., Field, T. S., Judge, J., Rochon, P., Harrold, L. R., Cadoret, C., ... David W. Bates (2005). The incidence of adverse drug events in two large academic long-term care facilities. The American Journal of Medicine, 118(3), 251-258. http://dx.doi.org/10.1016/j.amjmed.2004.09.018

Hair, J. F., Ringle, C. M., \& Sarstedt, M. (2011). PLS-SEM: Indeed a Silver Bullet. Journal of Marketing Theory and Practice, 19(2), 139-152. http://dx.doi.org/10.2753/MTP1069-6679190202

Hair, J., Hult, J., Ringle, C., \& Sarstedt, M. (2014). A primer on partial least squares structural equation modeling (PLS-SEM). SAGE Publications, Inc.

Hand, K., \& Barber, N. (2000). Nurses' attitudes and beliefs about medication errors in a UK hospital. International Journal of Pharmacy Practice, 8(2), 128-134. http://dx.doi.org/10.1111/j.2042-7174.2000. tb00997.x

Hayajneh, Y. A., AbuAlRub, R. F., \& Almakhzoomy, I. K. (2010). Adverse events in Jordanian hospitals: Types and causes. International Journal of Nursing Practice, 16(4), 374-380. http://dx.doi.org/10.1111/j. 1440-172X.2010.01854.X

Henseler, J., Ringle, C. M., \& Sinkovics, R. R. (2009). The use of partial least squares path modeling in international marketing. Advances in International Marketing (AIM), 20, 277-320. http://dx.doi.org/10. 1108/S1474-7979(2009)0000020014

Hoffman, J., \& Proulx, S. (2003). Medication errors caused by confusion of drug names. Drug Safety, 26(7), 445-452. http://dx.doi.org/10.2165/00002018-200326070-00001

Hofmann, D., \& Mark, B. (2006). An investigation of the relationship between safety climate and medication errors as well as other nurse and patient outcomes. Personnel Psychology, 59(4), 847-869. http://dx.doi.org/10.1111/j.1744-6570.2006.00056.x

Johnstone, M., \& Kanitsaki, O. (2006). The ethics and practical importance of defining, distinguishing and disclosing nursing errors: A discussion paper. International Journal of Nursing Studies, 43(3), 367-376. http://dx.doi.org/10.1016/j.jnurstu.2005.04.010

Kaushal, R., Bates, D. W., Landrigan, C., McKenna, K. J., Clapp, M. D., Federico, F., et al. (2001). Medication errors and adverse drug events in pediatric inpatients. Jama, 285(16), 2114-2120. http://dx.doi.org/ 10.1001/jama.285.16.2114

Keers, R. N., Williams, S. D., Cooke, J., \& Ashcroft, D. M. (2013). Causes of medication administration errors in hospitals: A systematic review of quantitative and qualitative evidence. Drug Safety, 36(11), 1045-1067. http://dx.doi.org/10.1007/s40264-013-0090-2

Kelly, W. (2004). Medication errors: Lessons learned and actions needed. Professional Safety, 49, 35-41.

Kohn, L. T., Corrigan, J. M., \& Donaldson, M. S. (2000). To err is human: Building a safer health system. Washington, DC: Institute of Medicine of the National Academy of Sciences.

Lan, Y. H., Wang, K. W., Yu, S., Chen, I. J., Wu, H. F., \& Tang, F. (2014). Medication errors in pediatric nursing: Assessment of nurses' knowledge and analysis of the consequences of errors. Nurse Education Today, 34(5), 821-828. http://dx.doi.org/10.1016/j.nedt.2013.07.019

Manojlovich, M., \& DeCicco, B. (2007). Healthy work environments, nurse-physician communication, and patients' outcomes. American Journal of Critical Care, 16(6), 536-543.

Mayo, A. M., \& Duncan, D. (2004). Nurse perceptions of medication errors: What we need to know for patient safety. Journal of Nursing Care Quality, 19(3), 209-217. http://dx.doi.org/10.1097/00001786 -200407000-00007

Mrayyan, M., Shishani, K., \& Al-Faouri, I. (2007). Rate, causes and reporting of medication errors in Jordan: Nurses' perspectives. Journal of Nursing Management, 15(6), 659-670. http://dx.doi.org/10.1111/j.13652834.2007.00724.x

Mrayyan, M., Shishani, K., Faouri, I., \& Ammouri, A. (2008). Nurses' perceptions of medication errors in Jordan. Jordan Medical Journal, 42(2), 94-105.

O'Shea, E. (1999). Factors contributing to medication errors: A literature review. Journal of Clinical Nursing, 8(5), 496-504. http://dx.doi.org/10.1046/j.1365-2702.1999.00284.x

Reason, J. (1990). Human error. Cambridge, UK: Cambridge university press. http://dx.doi.org/10.1017/CBO 9781139062367 
Reason, J. (1995). Understanding adverse events: Human factors. Quality in Health Care, 4(2), 80-89. http://dx.doi.org/10.1136/qshc.4.2.80

Reason, J. (2000). Human error: Models and management. BMJ, 320(7237), 768-770. http://dx.doi.org/10.1136 /bmj.320.7237.768

Scott, H. (2002). Increasing number of patients is being given wrong drugs. British Journal of Nursing, 11(1), 4. http://dx.doi.org/10.12968/bjon.2002.11.1.9324

Tang, F. I., Sheu, S. J., Yu, S., Wei, I. L., \& Chen, C. H. (2007). Nurses relate the contributing factors involved in medication errors. Journal of Clinical Nursing, 16(3), 447-457. http://dx.doi.org/10.1111/j. 1365-2702.2005.01540.x

Taxis, K., \& Barber, N. (2003). Causes of intravenous medication errors: An ethnographic study. Quality and Safety in Health Care, 12(5), 343-347. http://dx.doi.org/10.1136/qhc.12.5.343

Throckmorton, T., \& Etchegaray, J. (2007). Factors affecting incident reporting by registered nurses: The relationship of perceptions of the environment for reporting errors, knowledge of the nursing practice act, and demographics on intent to report errors. Journal of Peri Anesthesia Nursing, 22(6), 400-412. http://dx.doi.org/10.1016/j.jopan.2007.09.006

Veazie, P. J. (2006). An individual-based framework for the study of medical error. International Journal for Quality in Health Care, 18(4), 314-319. http://dx.doi.org/10.1093/intqhe/mzl011

Vincent, C., Taylor-Adams, S., \& Stanhope, N. (1998). Framework for analysing risk and safety in clinical medicine. BMJ: British Medical Journal, 316(7138), 1154-1157. http://dx.doi.org/10.1136/bmj.316. 7138.1154

Wakefield, B. J., Uden-Holman, T., \& Wakefield, D. S. (2005). Development and validation of the medication administration error reporting survey. Advances in Patient Safety, 4, 475-489.

Webster, C. S., \& Anderson, D. J. (2002). A practical guide to the implementation of an effective incident reporting scheme to reduce medication error on the hospital ward. International Journal of Nursing Practice, 8(4), 176-183. http://dx.doi.org/10.1046/j.1440-172X.2002.00368.x

Wright, K. (2010). Do calculation errors by nurses cause medication errors in clinical practice? A literature review. Nurse Education Today, 30(1), 85-97. http://dx.doi.org/10.1016/j.nedt.2009.06.009

\section{Copyrights}

Copyright for this article is retained by the author(s), with first publication rights granted to the journal.

This is an open-access article distributed under the terms and conditions of the Creative Commons Attribution license (http://creativecommons.org/licenses/by/3.0/). 